\title{
Distribution, Conjugation, and Excretion of Labeled Aldosterone in Congestive Heart Failure and in Controls with Normal Circulation: Develop- ment and Testing of a Model with an Analog Computer*
}

\author{
R. A. Cheville, J. A. Luetscher, $\dagger$ E. W. Hancock, A. J. Dowdy, And \\ G. W. Nokes \\ (From the Department of Medicine, Stanford University School of Medicine, Palo Alto, Calif.)
}

The distribution and clearance of aldosterone from plasma determine the fraction of secreted hormone reaching sites where the cellular actions of the hormone occur. Tait, Tait, Little, and Laumas (1) described the disappearance of aldosterone from plasma of normal man in terms of a two compartment system. Davis, Olichney, Brown, and Binnion (2) showed that the volumes of distribution and rates of clearance of aldosterone are reduced in dogs with experimental heart failure and low cardiac output. Our findings indicate that marked alterations in distribution and clearance of aldosterone are present in patients with congestive failure.

Tait, Little, Tait, and Flood (3) estimated the mean plasma concentration of aldosterone in human plasma from the secretion rate and the plasma clearance rate. Ayers and his colleagues (4) and Tait and associates (5) showed that hepatic clearance of aldosterone is subnormal in dogs or in man in congestive failure (4). Camargo, Dowdy, Hancock, and Luetscher (6) demonstrated that reduced hepatic clearance and extraction of aldosterone may contribute to an increased concentration in plasma of patients with heart failure.

The liver extracts aldosterone from plasma and returns conjugates and metabolites to plasma, in

\footnotetext{
* Submitted for publication February 8, 1966; accepted May 6, 1966.

These studies were supported by grant AM 03062 from the National Institute of Arthritis and Metabolic Diseases, which also awarded a traineeship (T1 AM 5021) and Research Career Award (K6 AM 14,176). Assistance from the General Clinical Research Center (FR-70) and from the Analog Computer Facility (HE-05847) is also gratefully acknowledged.

$\dagger$ Address requests for reprints to Dr. John A. Luetscher, Dept. of Medicine, Stanford University School of Medicine, Palo Alto, Calif. 94304.
}

which they circulate until they are excreted by the kidneys (7). The kidneys also extract aldosterone from plasma and produce a significant fraction of the acid-labile conjugate that appears in urine (7-10). The simple models previously proposed do not accurately fit the experimental data, and it has been difficult to describe quantitatively the production of acid-labile conjugate in the liver and kidneys.

Aldosterone distribution and metabolism can be simulated with the aid of an electrical analog computer. In the studies described in this report, subjects with normal circulation or congestive heart failure have received a loading dose and continuous infusion of labeled aldosterone. The measured concentrations of labeled aldosterone in arterial and renal venous plasma have been compared with the predictions of certain models in order to evaluate the distribution of aldosterone and its removal from plasma by the kidneys and liver. The appearance of labeled conjugate in plasma and urine has been examined to determine the formation, distribution, and excretion of acidlabile conjugate. Accurate simulation of observations during several types of study restricts the choice of models and constants to such an extent that a reasonably precise description of the system results. Data from a number of patients, analyzed in a similar fashion, permit comparisons of aldosterone metabolism between patients with normal circulation and those with congestive failure.

\section{Methods}

Labeled aldosterone ${ }^{1}\left(1,2-d\right.$-aldosterone- ${ }^{8} \mathrm{H}, 80 \mu \mathrm{c}$ per $\mu \mathrm{g})$ was checked for purity on receipt and at regular

1 Obtained through the generosity of the Endocrinology Study Section, National Institutes of Health. 
TABLE I

Clinical information and data from cardiac catheterization

\begin{tabular}{|c|c|c|c|c|c|c|c|c|}
\hline Patient & $\begin{array}{l}\text { Type of } \\
\text { study }\end{array}$ & Age and sex & $\begin{array}{l}\text { Body surface } \\
\quad \text { area }\end{array}$ & Diagnosis* & $\begin{array}{c}\text { Cardiac } \\
\text { index }\end{array}$ & $\begin{array}{c}\text { Arterial } \\
\text { oxygen } \\
\text { saturation }\end{array}$ & $\begin{array}{c}\text { Systemic } \\
\text { a-v Oz } \\
\text { difference }\end{array}$ & $\begin{array}{l}\text { Creatinine } \\
\text { clearance }\end{array}$ \\
\hline & & & $m^{2}$ & & $L / \min / m^{2}$ & $\%$ & $\mathrm{ml} / 100 \mathrm{ml}$ & $m l / m i n$ \\
\hline \multicolumn{9}{|c|}{ Controls: no heart disease } \\
\hline 17 & A & $25 \mathrm{M}$ & 2.05 & Normal & & & & 116 \\
\hline 18 & $\mathrm{~A}$ & $58 \mathrm{M}$ & 2.00 & Anxiety & & & & 120 \\
\hline 19 & A & $55 \mathrm{M}$ & 1.65 & Chest pain & & & & 100 \\
\hline 20 & B & $21 \mathrm{M}$ & 1.94 & Hematuria & & & & 180 \\
\hline 21 & B & $44 \mathrm{M}$ & 2.35 & Obesity & & & & 90 \\
\hline \multicolumn{9}{|c|}{ Asymptomatic heart disease } \\
\hline 22 & B & $36 \mathrm{M}$ & 1.93 & RHD, MS & 2.7 & 94 & 4.4 & 152 \\
\hline 23 & $\mathrm{C}$ & $40 \mathrm{~F}$ & 1.65 & Postoperative AS & 3.7 & 96 & 4.3 & 130 \\
\hline \multicolumn{9}{|c|}{ Minimal to moderate failure } \\
\hline 24 & $\mathrm{D}$ & $45 \mathrm{~F}$ & 1.80 & RHD, MI, ms, as & 2.75 & 91 & 5.3 & 114 \\
\hline 25 & C & $47 \mathrm{M}$ & 1.94 & RHD, MS & 2.65 & 95 & 5.4 & 124 \\
\hline 26 & D & $52 \mathrm{~F}$ & 1.83 & RHD, MS, mi & 2.50 & 89 & 5.1 & 62 \\
\hline 27 & $\mathrm{C}$ & $44 \mathrm{~F}$ & 1.72 & RHD, MS, ai & 2.45 & 98 & 5.3 & 105 \\
\hline 33 & $\mathrm{D}$ & $35 \mathrm{M}$ & 1.92 & $\mathrm{RHD}, \mathrm{AI}, \mathrm{mi}$ & 2.24 & 97 & 7.1 & 86 \\
\hline \multicolumn{9}{|c|}{ Advanced congestive failure } \\
\hline 28 & $\mathrm{C}$ & $44 \mathrm{~F}$ & 1.72 & RHD, MS, MI & 1.90 & 97 & 7.0 & 95 \\
\hline 29 & $\mathrm{D}$ & $42 \mathrm{~F}$ & 1.57 & RHD, MS, MI & 1.89 & 95 & 6.5 & 60 \\
\hline 30 & $\mathrm{D}$ & $50 \mathrm{~F}$ & 1.76 & Pat. duct. art. & 1.73 & 97 & 7.3 & 68 \\
\hline 31 & $\mathrm{D}$ & $55 \mathrm{M}$ & 1.67 & ASHD, mi & 1.64 & 96 & 8.6 & 52 \\
\hline
\end{tabular}

${ }^{*} \mathrm{RHD}=$ rheumatic heart disease; $\mathrm{ASHD}=$ arteriosclerotic heart disease $;$ pat. duct. art. = patent ductus arteriosus. Major valve lesion in capitals, minor in lower case. $\mathrm{M}=$ mitral; $\mathrm{A}=$ aortic; $\mathrm{S}=$ stenosis; $\mathrm{I}=$ incompetency.

intervals. It was dried to remove benzene, dissolved in ethanol, and stored at $-25^{\circ} \mathrm{C}$. Immediately before use, it was diluted in isotonic saline solution to a concentration of $10 \mu \mathrm{c}$ per $50 \mathrm{ml}$. Measured volumes of this solution were loaded into syringes for the initial injection and for a continuous infusion delivered through a short length of plastic tubing from a motor-driven syringe at a rate of $0.4 \mathrm{ml}$ per minute. Samples of all solutions were saved for counting. Blood was drawn from an artery, peripheral vein, or venous catheter inserted into the arm opposite that used for infusion. Blood samples were chilled to $4^{\circ} \mathrm{C}$ and centrifuged. Plasma was analyzed for radioactivity as free aldosterone and as acid-labile conjugate by the methods previously reported $(6,8)$. In each case, aldosterone- ${ }^{8} \mathrm{H}$, extracted with methylene dichloride, was purified by chromatography before and after acetylation. Recovery was controlled by aldosterone- ${ }^{14} \mathrm{C}$ added to each sample of plasma or conjugate before extraction. Tritium and ${ }^{14} \mathrm{C}$ were counted in a liquid scintillation spectrometer until random error was less than $3 \%$. Conjugates were concentrated and separated from plasma proteins (8), and the concentrate was further extracted with methylene dichloride to remove any traces of free aldosterone. A correction for recovery of acid-labile conjugate from this procedure (average $83 \% \pm \mathrm{SE} 5 \%$ ) was made in order to make the over-all recovery from plasma comparable to that from urine. The conjugate was then hydrolyzed at $\mathrm{pH} 1$ for 24 hours, yielding free aldosterone, which was extracted, purified, and counted.
Blood samples were divided and analyzed in duplicate whenever possible. The mean coefficient of variation between duplicates was $4 \%$ for free aldosterone and $8 \%$ for the conjugate. Urine was collected at stated intervals, and labeled aldosterone and conjugate were measured as previously described (8).

Plans of study. Five control subjects without known disease and one patient with asymptomatic heart disease were studied according to plan A or B. These subjects received a measured dose of aldosterone- ${ }^{8} \mathrm{H}$ in 1 minute, followed by a sustaining infusion. In plan $A$, the first blood sample was drawn within 4 minutes after the initial dose, followed by additional samples during and after an infusion lasting 20 to 90 minutes. In plan B, blood samples were drawn at the midpoint of hourly urine collections for 3 hours.

Sixteen patients were studied during cardiac catheterization, performed for evaluation of valvular disease or septal defect. Clinical information and data from cardiac catheterization are given in Table I. Additional analyses are presented from Patients 2, 8, 11, 12, and 16, who were described in a previous report (6).

In 13 patients, blood was obtained from a renal vein, which was identified by the position of the catheter tip, by the high oxygen content, and by an extraction ratio of Hippuran- ${ }^{191} \mathrm{I}$ of greater than $50 \%$ in whole blood or of 72 to $85 \%$ in plasma (11). Two plans were used to study the uptake and release of aldosterone and conjugate by the kidneys. In plan $\mathrm{C}$, in order to approach equilibrium, a continuous infusion of labeled aldosterone 


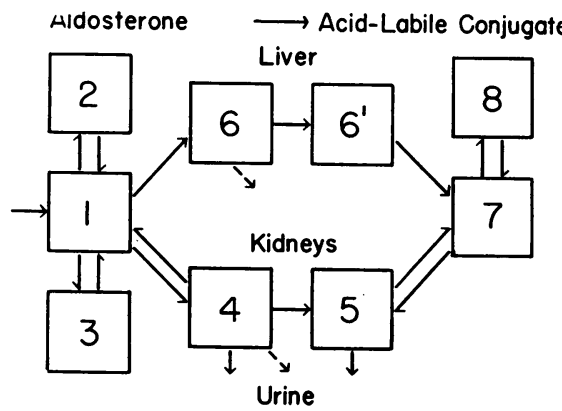

Fig. 1. Model of aldosterone distribution, conjugaTION, AND EXCRETION.

was given for 1 to 2 hours. Simultaneous samples of arterial and renal venous blood were drawn during the last 20 to 30 minutes of infusion. In plan $\mathrm{D}$, arterial and renal venous samples were drawn at $2.5,10$, and $20 \mathrm{~min}$ utes after the initial loading dose of labeled aldosterone, in order to observe the uptake and release of labeled aldosterone and conjugate before the establishment of equilibrium.

To obtain accurate estimates of renal plasma flow, we administered $2 \mu \mathrm{c}$ Hippuran- ${ }^{131} \mathrm{I}$ intravenously, followed by a continuous infusion from a motor-driven syringe at a measured rate sufficient to sustain a level of 100 to 150 cpm per $\mathrm{ml}$ of plasma. High specific activity material ${ }^{2}$ was used, since there is evidence (12) that the excretion of acid-labile conjugate may be depressed by high blood levels of substances that compete for transport in the renal tubules. Batches found to contain detectable inorganic ${ }^{131} \mathrm{I}$ were rejected. Plasma Hippuran- ${ }^{131} \mathrm{I}$ was measured in a gamma-ray scintillation spectrometer.

The clearance of Hippuran- ${ }^{181} \mathrm{I}$ was estimated by two methods. When a constant concentration of ${ }^{131} \mathrm{I}$ in plasma was reached, the clearance was estimated by dividing the infusion rate by the plasma concentration. When equilibrium was not achieved, the plasma Hippuran- ${ }^{181} \mathrm{I}$ determinations were simulated on the analog computer, with a two compartment system; and the rate of clearance from plasma giving the best approximation of the observed data on plasma and urine was selected. The two methods agreed within the accuracy of counting (3\%) when a stable plasma concentration of Hippuran was reached, as was usual in study plan C. Under study plan $\mathrm{D}$, equilibrium was not regularly achieved. In the latter instances, the range of estimates of Hippuran clearance that accurately simulated the measurements varied by less than $10 \%$ from the mean value given in Tables IV and V. Renal plasma flow was calculated by dividing the clearance by the fraction of Hippuran extracted by the kidneys.

The presence of ${ }^{131} \mathrm{I}$ did not cause difficulty in counting tritium, owing to the difference in energy of the radiation produced by the two isotopes. Since ${ }^{181} \mathrm{I}$ interferes with ${ }^{14} \mathrm{C}$ counting, the following precautions were taken. Samples containing ${ }^{181} \mathrm{I}$ were counted after the end of the

2 Volk Radiochemical Co., Chicago, Ill. test. Plasma and urine samples were held at $-25^{\circ}$ for several weeks pending the decay of radioactive iodine. Very little iodine was extracted with methylene dichloride, and most of this was eliminated during purification of aldosterone and conjugate. Vials containing purified aldosterone diacetate were held until no ${ }^{131} \mathrm{I}$ was detectable and until the higher energy region showed no measurable decay of counting rate.

Testing of models and estimation of parameters. The electrical analog computer was selected for the first studies. Voltages representing aldosterone- ${ }^{8} \mathrm{H}$ administered in the initial dose and sustaining infusion were introduced into an integrator, representing the initial compartment. The flow of aldosterone from compartment 1 into outer compartments $2,3, \ldots$ was assumed to be proportional to the quantity $Q_{1}$ in the compartment and to constants $\lambda_{21,31} \ldots$. The return flow was also included, giving the differential equation for compartment 1 : $\mathrm{dQ}_{1} / \mathrm{dt}=$ (infusion rate $)-\mathrm{Q}_{1}\left(\lambda_{21}+\lambda_{31}+\ldots\right)+\lambda_{12} \mathrm{Q}_{2}$ $+\lambda_{13} Q_{3}+\ldots$.

Since the concentration of aldosterone- ${ }^{3} \mathrm{H}$ in plasma $\mathrm{C}_{1}$ was measured, the initial volume of distribution $\mathrm{V}_{1}$ can be calculated: $V_{1}=Q_{1} / C_{1}$, and the clearance $C L_{21}$ from plasma can be estimated: $C_{21}=V_{1} \lambda_{21}$. In the case of compartments from which samples were not taken, the estimation of volume requires additional assumptions. The kidneys represent a special case, in that the clearance of aldosterone from plasma could be calculated from measurements of the arteriovenous difference and of the renal plasma flow. Concentrations in renal venous plasma were simulated by the method described in the Appendix.

Each compartment of the model to be tested was represented by an integrator, and the equations were reflected by the analog circuit. The simplest models were tested first. If no combination of reasonable values for parameters could be found that would simulate the experimental data, the simplest effective modification of the model was introduced. The final model, which has been used to analyze all data, is shown in Figure 1.

Aldosterone $-{ }^{3} \mathrm{H}$ is injected into plasma compartment 1 , from which it can enter (and return from) compartments 2 and 3, which are not anatomically defined. Aldosterone- ${ }^{3} \mathrm{H}$ entering the kidneys, compartment 4 , can return to plasma, be excreted unchanged into urine, form acidlabile conjugate, or emerge as other, unspecified metabolites. The liver, compartment 6 , also clears aldosterone from plasma, forming various conjugates and metabolites.

Acid-labile conjugate is formed in the kidneys (compartment 5) and in the liver (compartment $6^{\prime}$ ). The right-hand side of the model shows the distribution of acid-labile conjugate in plasma (compartment 7) and extravascular space (compartment 8) and its excretion through the kidneys.

Experimental data comprise measurements of free aldosterone and acid-labile conjugate in blood plasma from an artery and from regional veins and of labeled aldosterone and acid-labile conjugate in urine. In the simulation, various volumes of distribution and rates of transfer between compartments were tested in an orderly fashion until the output approximated the experimental data 
TABLE II

Two pool model of distribution and clearance of aldosterone from plasma: best estimates of inner volume $\left(\mathrm{V}_{1}\right)$ and fraction transferred per minute $(\lambda)^{*}$

\begin{tabular}{|c|c|c|c|c|c|c|c|c|}
\hline \multirow[b]{2}{*}{ Patient } & \multicolumn{4}{|c|}{ Normal controls } & \multicolumn{4}{|c|}{ Congestive failure } \\
\hline & 17 & 18 & 19 & Mean & 24 & 26 & 33 & 31 \\
\hline $\mathrm{V}_{1}, L$ & $\begin{array}{r}26.7 \\
\pm 2.6\end{array}$ & $\begin{array}{r}31.3 \\
\pm 2.7\end{array}$ & $\begin{array}{r}23.6 \\
\pm 1.5\end{array}$ & 27.2 & $\begin{array}{r}6.00 \\
\pm 0.39\end{array}$ & $\begin{array}{r}4.38 \\
\pm 0.14\end{array}$ & $\begin{array}{r}3.88 \\
\pm 0.04\end{array}$ & $\begin{array}{r}3.81 \\
\pm 0.02\end{array}$ \\
\hline$\lambda_{21}$ & $\begin{array}{r}0.10 \\
\pm 0.02\end{array}$ & $\begin{array}{r}0.10 \\
\pm 0.02\end{array}$ & $\begin{array}{r}0.11 \\
\pm 0.02\end{array}$ & 0.10 & $\begin{array}{r}0.13 \\
\pm 0.01\end{array}$ & $\begin{array}{r}0.17 \\
\pm 0.01\end{array}$ & $\begin{array}{r}0.10 \\
\pm 0.01\end{array}$ & $\begin{array}{r}0.13 \\
\pm 0.01\end{array}$ \\
\hline$\lambda_{12}$ & $\begin{array}{r}0.071 \\
\pm 0.015\end{array}$ & $\begin{array}{r}0.087 \\
\pm 0.015\end{array}$ & $\begin{array}{r}0.083 \\
\pm 0.010\end{array}$ & 0.080 & $\begin{array}{r}0.045 \\
\pm 0.009\end{array}$ & $\begin{array}{r}0.043 \\
\pm 0.008\end{array}$ & $\begin{array}{r}0.028 \\
\pm 0.004\end{array}$ & $\begin{array}{r}0.015 \\
\pm 0.002\end{array}$ \\
\hline$\lambda_{01}$ & $\begin{array}{r}0.044 \\
\pm 0.005\end{array}$ & $\begin{array}{r}0.055 \\
\pm 0.005\end{array}$ & $\begin{array}{r}0.061 \\
\pm 0.004\end{array}$ & 0.053 & $\begin{array}{r}0.201 \\
\pm 0.018\end{array}$ & $\begin{array}{r}0.180 \\
\pm 0.010\end{array}$ & $\begin{array}{r}0.215 \\
\pm 0.007\end{array}$ & $\begin{array}{r}0.034 \\
\pm 0.010\end{array}$ \\
\hline
\end{tabular}

${ }^{*} \lambda_{\mathrm{ij}}=$ fraction transferred into compartment $\mathrm{i}$ from $\mathrm{j}$ per minute. Each estimate $\pm 1 \mathrm{SD}$.

(least squares fit), beginning with free aldosterone and proceeding to acid-labile conjugate. In Figures 2 through 9 , experimental data are compared with the computed analog curves.

To test the estimates by an independent method, we used a digital computer program for analysis of multicom-

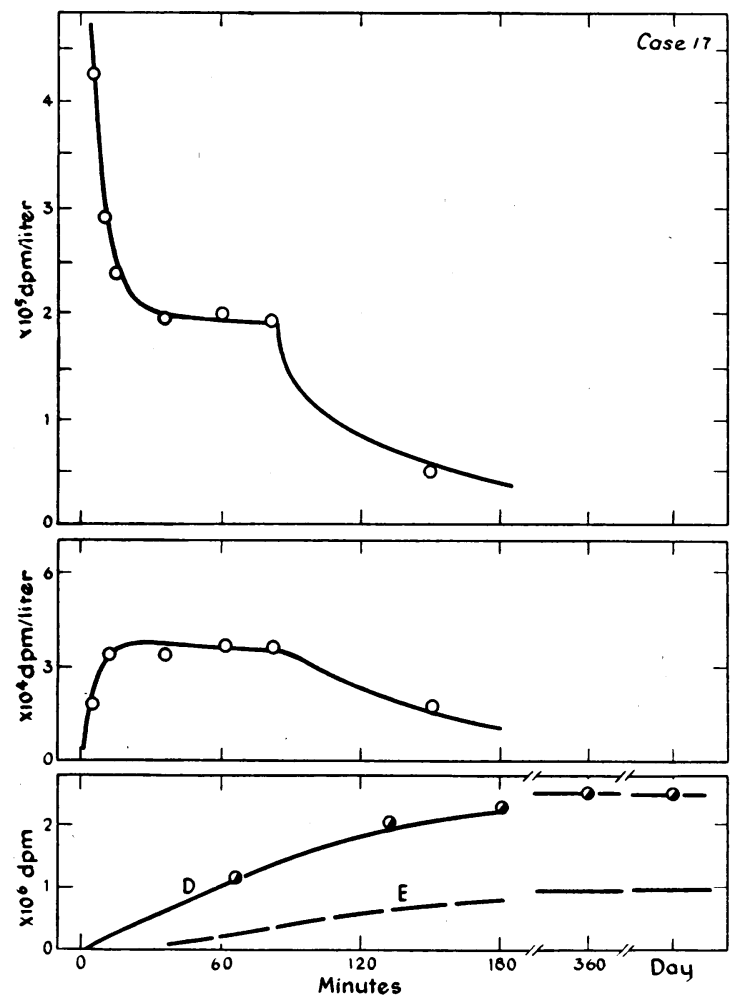

Fig. 2. Data from normal control, Subject 17. Top: Aldosterone- ${ }^{8} \mathrm{H}$ in plasma. Center: Labeled conjugate in plasma. Bottom: Labeled conjugate in urine (curve D), after initial dose of $8.1 \mu \mathrm{c}$ and infusion of $8.0 \mu \mathrm{c}$ from 1 to 83 minutes. Curve $\mathrm{E}$ is conjugate extracted from plasma. partmental systems, as suggested by Berman (13). The parameters and statistical information derived from this program are given in Table II and in the text.
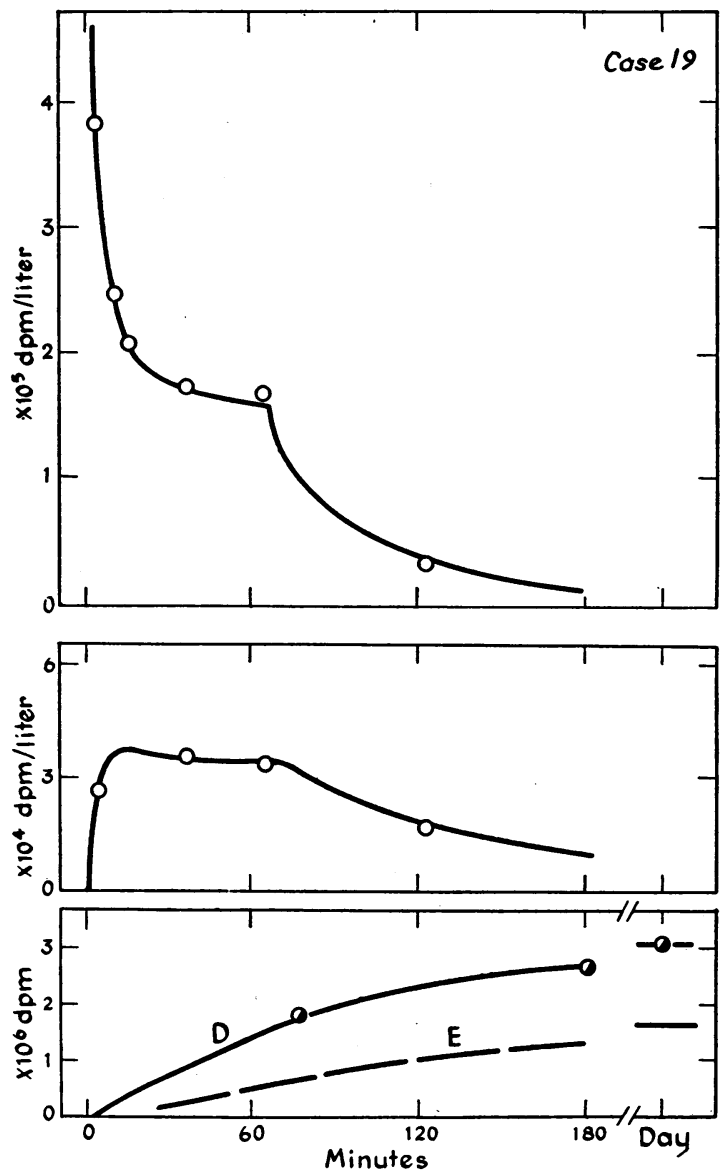

Fig. 3. Data from control, Subject 19. Displayed as in Figure 2. Initial dose, $6.9 \mu \mathrm{c}$. Infusion, $6.0 \mu \mathrm{c}$ from 1 to 66 minutes. 

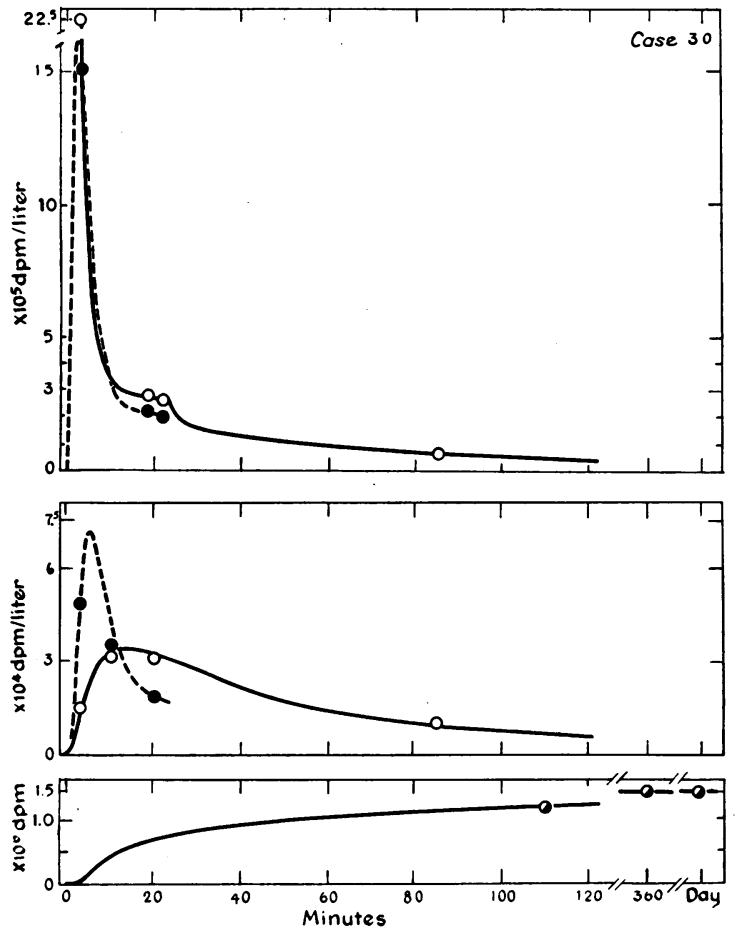

Fig. 4. Data from Patient 30 with advanced failURE. Top: Concentration of aldosterone $-{ }^{3} \mathrm{H}$ in plasma from artery (open circles) and renal vein (solid circles). Center: Concentration of acid-labile conjugate in artery (open circles) and renal vein (solid circles). Bottom: Appearance of acid-labile conjugate in urine. Initial dose, $7.4 \mu \mathrm{c}$. Infusion, $1.6 \mu \mathrm{c}$ given from 1 to 21 minutes.

\section{Results}

\section{Distribution and clearance of aldosterone from plasma}

A two pool model has been used to simulate aldosterone distribution in normal subjects. The results presented in Table II are in accord with previous observations $(1,9)$, indicating an inner volume $\mathrm{V}_{1}$ averaging $27.2 \mathrm{~L}$ in normal men. In four patients with congestive failure, the mean inner volume of distribution was $4.5 \mathrm{~L}$. Individual estimates were between 3.8 and $6 \mathrm{~L}$, with a coefficient of variation averaging less than $3 \%$. These estimates reflect the marked difference in concentration of labeled aldosterone in plasma drawn within a few minutes after initial injection, when the concentration of aldosterone $-{ }^{3} \mathrm{H}$ is lower in the normal subjects (Figures 2 and 3 ) than in patients with heart failure (Figures 4 and 5). A very rapid fall in aldosterone- ${ }^{3} \mathrm{H}$ concentration fol- lows the end of infusion of labeled aldosterone in the patient with heart failure (Figure 6).

The small inner volume in congestive heart failure is accompanied by reduced rates of clearance of aldosterone from plasma into the outer compartment and into the liver. The fraction of labeled aldosterone transferred to the outer compartment $\left(\lambda_{21}\right)$ is not significantly reduced, since both the volume and clearance fall to an equal extent. The fraction of aldosterone in $\mathrm{V}_{1}$ metabolized per unit time $\left(\lambda_{01}\right)$ actually rises in moderate congestive failure, since the contraction of $V_{1}$ is proportionately greater than the reduction of metabolic clearance rate. On the other hand, the return of labeled aldosterone from the outer compartment $\left(\lambda_{12}\right)$ falls progressively with advancing heart failure. These changes account for the abrupt rise and fall of aldosterone concentration with changes in the rate of administration observed in patients with congestive failure (Figures 4 to 6$)$.

A three pool model of aldosterone distribution has also been tested in normal men and in patients with normal circulation (Table III). In this al-
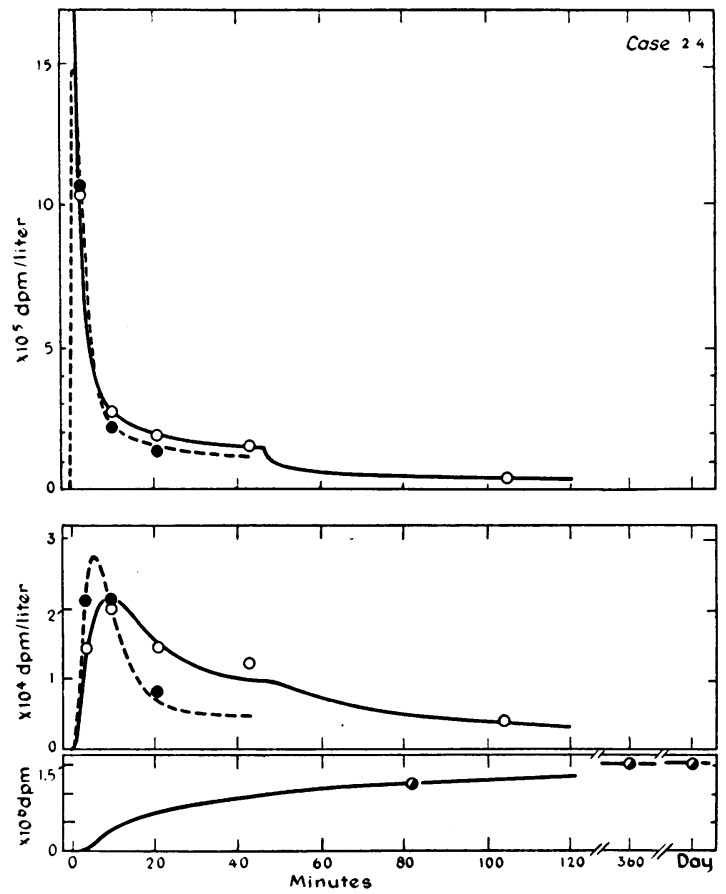

Fig. 5. Data from Patient 24 with moderate failURE. Changes in plasma aldosterone ${ }^{3} \mathrm{H}$ (top) and acidlabile conjugate (middle) immediately after initial dose, $6.9 \mu \mathrm{c}$. Infusion, $2.9 \mu \mathrm{c}$ from 1 to 46 minutes. 


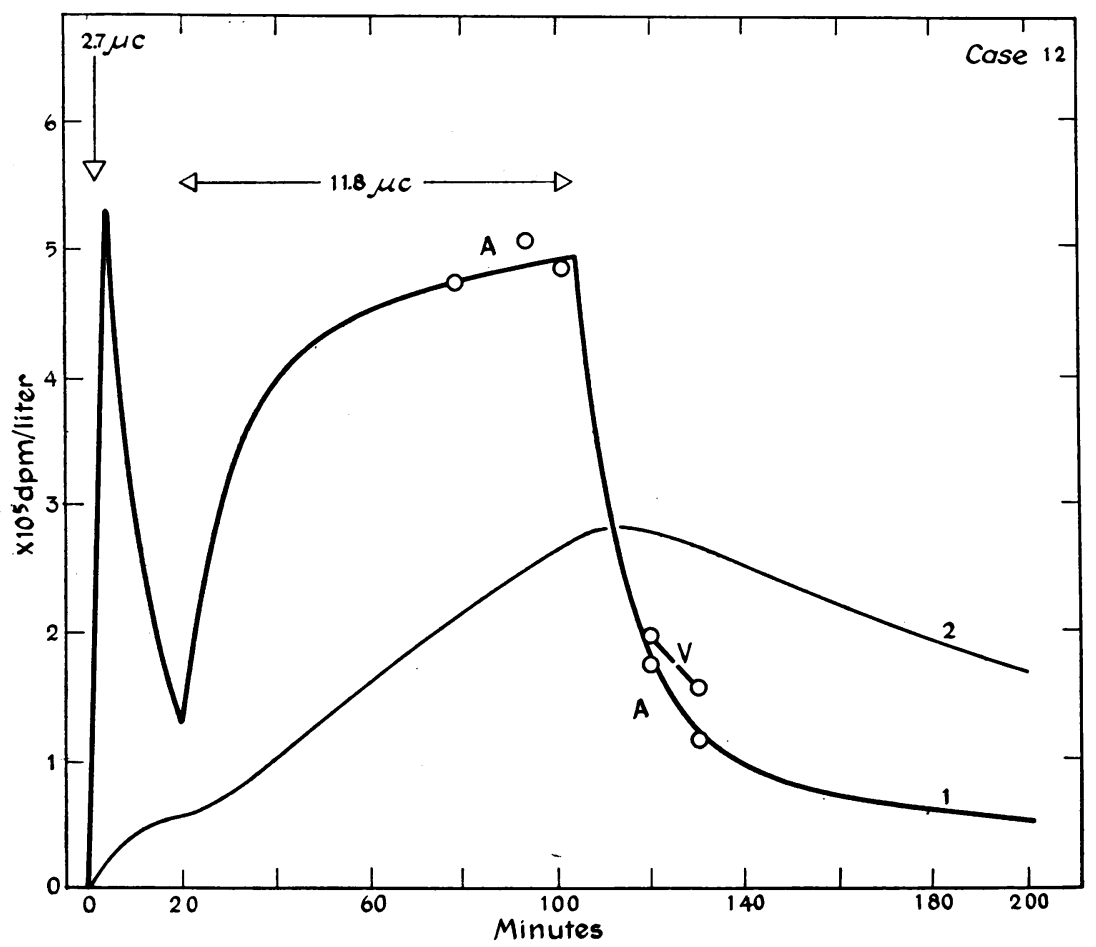

Fig. 6. Concentration of aldosterone- ${ }^{3} \mathrm{H}$ in plasma in Patient 12 . Analytical data in arterial plasma (A) and in antecubital venous plasma (V). Computed curves in inner (1) and outer (2) compartments. Initial dose, $2.7 \mu \mathrm{c}$. Infusion, $11.8 \mu \mathrm{c}$ from 20 to 100 minutes.

ternative model, the inner volume of distribution is equated to the plasma volume plus the fraction $(25 \%)$ of the red blood cell volume into which aldosterone penetrates rapidly (5). The outer volumes are $\mathrm{V}_{2}$, which equilibrates slowly with plasma, as in the two pool model; and $\mathrm{V}_{3}$, which equilibrates rapidly with plasma. Although the data can be simulated more exactly with the three pool model, the parameters have wider confidence limits and can be defined only when blood samples are drawn at frequent intervals after the initial injection of tracer.

When the normal clearances derived from the three pool model are compared with clearances of patients with congestive failure (Table IV), it is evident that advancing heart failure is associated with a progressive reduction in clearances of aldosterone from plasma into the "outer pool," the liver, and the kidneys. Since there is no evident advantage or justification for assuming the existence of three pools in the patients with congestive failure, a two pool model has been used. If a three pool model is used, the estimated clearances are similar to those given in Table IV, but they have much larger standard deviations than those indicated in Table II.

Renal extraction of aldosterone from plasma has been measured in 13 patients by drawing blood from an artery and from the renal vein (Tables III and IV).

When renal venous blood was collected within 3 minutes after a loading dose of aldosterone- ${ }^{3} \mathrm{H}$, a renal extraction ratio as high as 0.45 was noted in Patients 26, 29, and 30. This was followed by a period of reduced extraction while arterial aldosterone- ${ }^{3} \mathrm{H}$ was falling, and later by an approach to a steady state extraction near 0.20 after 20 to 60 minutes of constant infusion. These findings can be simulated (Figures 4 and 5 ) by assuming a renal volume of approximately $300 \mathrm{ml}$. Aldosterone is cleared from plasma at a rate equal to the renal plasma flow, whereas the reverse flow from kidney into plasma is assumed to be one-third of the entry rate. In the steady state, the kidneys extract approximately 20\% ( \pm SE $2 \%$ ) of arterial aldosterone over a wide range of renal plasma flow 
( 850 to $160 \mathrm{ml}$ per minute). The renal clearance of aldosterone in the steady state is proportional to renal plasma flow, which is markedly depressed in advanced congestive failure (Tables III and IV).

Only a small fraction $(3.5 \% \pm \mathrm{SE} 0.5 \%)$ of the aldosterone- ${ }^{3} \mathrm{H}$ extracted from plasma appears in the urine unchanged. It is necessary to assume conjugation or degradation of over $95 \%$ of aldosterone removed from plasma by the kidneys. Since aldosterone in the renal pool appears to equilibrate rapidly with plasma aldosterone, the rate of formation of conjugate in the kidneys $\left(\lambda_{54}\right)$ is limited by cellular transport or enzymatic activity, and not by availability of substrate in the pool.

Hepatic clearance of aldosterone from plasma is responsible for $85 \%$ of the total plasma clearance, according to Tait and associates' estimates (5). This figure, added to our estimates of renal ex- traction ( 8.5 to $20 \%$ of plasma clearance), would account for virtually all of the irreversible clearance of aldosterone from plasma. The hepatic and renal clearances of aldosterone from plasma have been estimated in Tables IV and V. Increasing signs of congestive failure are accompanied by a progressive fall in hepatic clearance.

Production, distribution, and excretion of acidlabile conjugate

Hepatic production of acid-labile conjugate has been demonstrated (14), but is considered inadequate to account for the observed excretion rate of conjugate $(7-10)$. The present studies are designed to demonstrate the formation of acidlabile conjugate in the kidneys and to compare the production rate in the kidneys with that occurring in other sites, principally in the liver.

Formation of acid-labile conjugate in the kidneys is indicated by the appearance of labeled con-

TABLE III

Volumes of distribution and clearances of aldosterone and acid-labile conjugate

\begin{tabular}{|c|c|c|c|c|c|c|c|c|c|c|c|}
\hline & & \multicolumn{6}{|c|}{ Normal circulation } & \multicolumn{4}{|c|}{ Asymptomatic } \\
\hline \multicolumn{2}{|c|}{ Patient: } & 17 & 18 & 19 & 20 & 21 & Mean & 22 & 23 & 16 & Mean \\
\hline \multicolumn{2}{|c|}{ Compartment no. } & \multicolumn{10}{|c|}{ Aldosterone: volume $(L)$} \\
\hline $\begin{array}{l}\text { Plasma } \\
\text { Outer } \\
\text { Outer }\end{array}$ & $\begin{array}{l}1 \\
3 \\
2\end{array}$ & $\begin{array}{l}3.8 \\
9 \\
44\end{array}$ & $\begin{array}{l}4.0 \\
10 \\
33\end{array}$ & $\begin{array}{l}4.0 \\
10 \\
33\end{array}$ & $\begin{array}{l}4.0 \\
12^{*} \\
36\end{array}$ & $\begin{array}{l}4.0 \\
15^{*} \\
31\end{array}$ & $\begin{array}{l}4.0 \\
10 \\
35\end{array}$ & $\begin{array}{l}4.0 \\
12^{*} \\
20\end{array}$ & $\begin{array}{l}4.0 \\
15^{*} \\
32\end{array}$ & $\begin{array}{l}4.0 \\
15^{*} \\
13\end{array}$ & 4.0 \\
\hline Into no. & From no. & \multicolumn{10}{|c|}{ Aldosterone: clearance $(L / \min )$} \\
\hline $\begin{array}{ll}\text { Outer } & 3 \\
\text { Outer } & 2 \\
\text { Liver } & 6 \\
\text { Kidney } & 4\end{array}$ & $\begin{array}{ll}\text { Plasma } & 1 \\
\text { Plasma } & 1 \\
\text { Plasma } & 1 \\
\text { Plasma } & 1\end{array}$ & $\begin{array}{l}5 \\
1.9 \\
1.00 \\
0.65\end{array}$ & $\begin{array}{l}5 \\
1.6 \\
1.50 \\
0.70\end{array}$ & $\begin{array}{l}5 \\
2.0 \\
1.30 \\
0.60\end{array}$ & $\begin{array}{l}5^{*} \\
1.6 \\
1.02 \\
0.85\end{array}$ & $\begin{array}{l}5^{*} \\
2.0 \\
0.77 \\
0.45\end{array}$ & $\begin{array}{l}5 \\
1.8 \\
1.12 \\
0.65\end{array}$ & $\begin{array}{l}5^{*} \\
1.2 \\
1.13 \\
0.80\end{array}$ & $\begin{array}{l}4^{*} \\
1.6 \\
0.75 \\
0.53\end{array}$ & $\begin{array}{l}2.5^{*} \\
1.0 \\
0.70 \\
0.85\end{array}$ & $\begin{array}{l}1.3 \\
0.86 \\
0.73\end{array}$ \\
\hline & \multicolumn{10}{|c|}{ Aldosterone: renal extraction and conjugation (steady state, fraction) } \\
\hline \multicolumn{2}{|c|}{ Extraction $(a-v) / a \dagger$} & \multicolumn{5}{|c|}{, (Computed $=0.20 \pm 0.02 \ddagger)$} & \multicolumn{2}{|c|}{ Observed $=$} & \multirow{2}{*}{$\begin{array}{c}0.16 \\
\pm 0.02 \ddagger \\
0.10\end{array}$} & \multirow{2}{*}{$\begin{array}{c}0.21 \\
\pm 0.01 \ddagger \\
0.22\end{array}$} & 0.185 \\
\hline Conjugatior & $\lambda_{54}$ & 0.15 & 0.19 & 0.15 & 0.20 & 0.12 & 0.16 & 0.21 & & & 0.18 \\
\hline \multicolumn{2}{|c|}{ Compartment no. } & \multicolumn{10}{|c|}{ Conjugate: volume $(L)$} \\
\hline $\begin{array}{l}\text { Plasma } \\
\text { Outer }\end{array}$ & $\begin{array}{l}7 \\
8\end{array}$ & 4.5 & $\begin{array}{l}3.3 \\
16\end{array}$ & 20 & 20 & $20^{3.0}$ & 19.6 & $\begin{array}{l}3.0 \\
10\end{array}$ & 3.3 & 25 & $\begin{array}{r}3.4 \\
17.5\end{array}$ \\
\hline Into no. & From no. & \multicolumn{10}{|c|}{ Conjugate: clearance $(L / \min )$} \\
\hline \multirow{2}{*}{\multicolumn{2}{|c|}{$\begin{array}{ll}\text { Outer } & 8 \\
\text { Kidney } & 5\end{array}$}} & 0.65 & $\begin{array}{r}0.10 \\
.70\end{array}$ & $\begin{array}{l}0.35 \\
0.60\end{array}$ & $\begin{array}{l}0.60^{*} \\
0.85\end{array}$ & $\begin{array}{l}0.02 * \\
0.45\end{array}$ & $\begin{array}{l}0.22 \\
0.65\end{array}$ & $\begin{array}{l}0.40^{*} \\
0.80\end{array}$ & 0.53 & $\begin{array}{l}0.70^{*} \\
0.85\end{array}$ & 0.73 \\
\hline & & \multicolumn{10}{|c|}{ Conjugate: renal extraction and excretion (steady state, fraction) } \\
\hline \multirow{2}{*}{\multicolumn{2}{|c|}{$\begin{array}{l}\text { Extraction, computed } \\
\text { Extraction, observed } \\
\text { Excretion } \lambda_{05}\end{array}$}} & .27 & 0.30 & 0.43 & 0.24 & 0.21 & 0.29 & 0.23 & $\begin{array}{l}0.33 \\
0.34\end{array}$ & $\begin{array}{l}0.20 \\
0.21\end{array}$ & 0.25 \\
\hline & & 2.0 & 3.3 & 3.3 & 2.5 & 1.0 & 2.4 & 3.3 & 2.2 & 2.7 & 2.7 \\
\hline
\end{tabular}

*Nominal value, used to fit curve to data, but poorly defined because first blood sample was drawn 20 minutes after injection; not included in average.

$\dagger$ Arterial minus venous aldosterone divided by arterial aldosterone.

$\ddagger$ Standard deviation. 
TABLE IV

Volumes of distribution and clearances of aldosterone and acid-labile conjugate

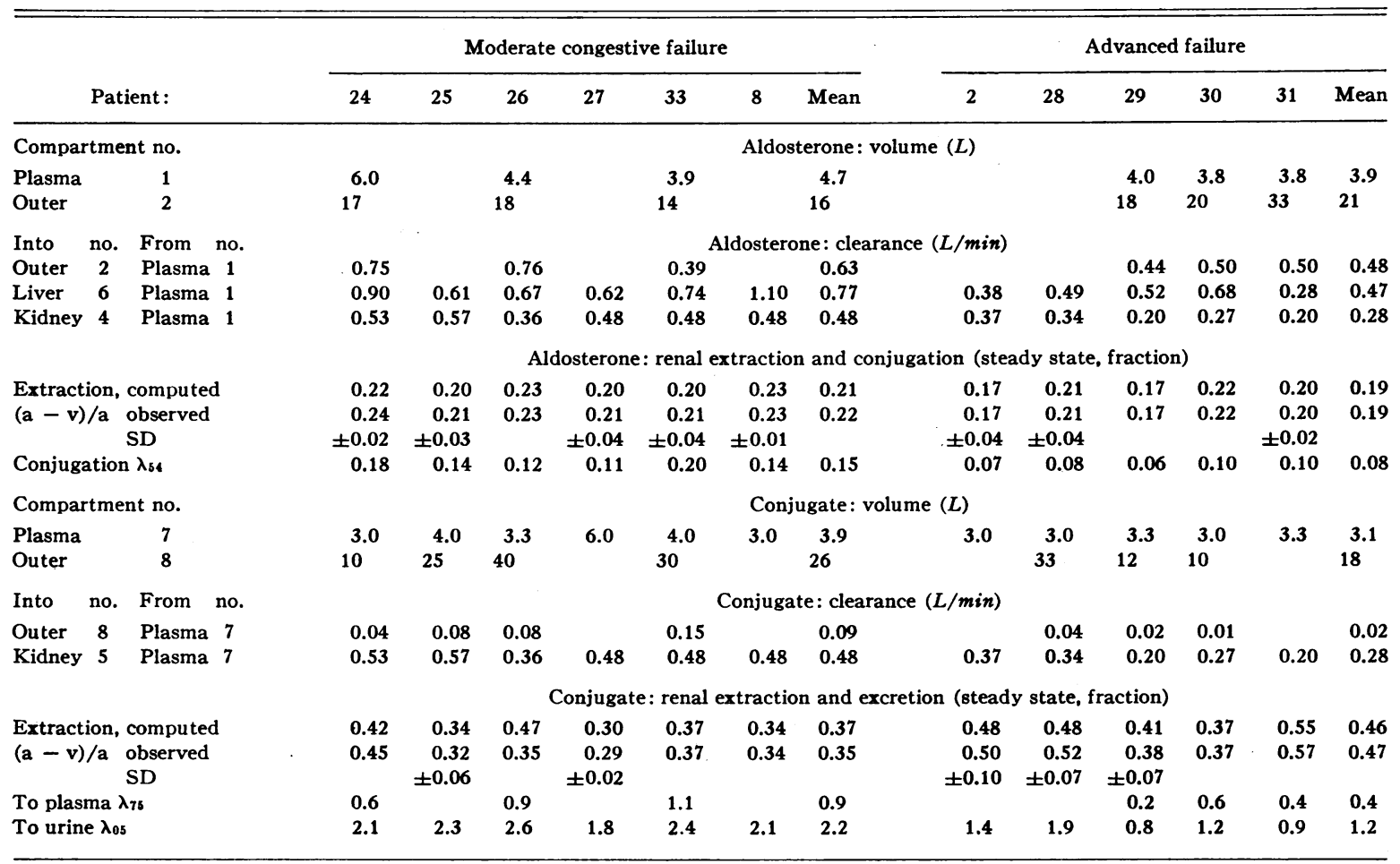

TABLE V

Comparison of renal with hepatic and other sites of aldosterone metabolism*

\begin{tabular}{|c|c|c|c|c|}
\hline $\begin{array}{l}\text { Group: } \\
\text { No. of patients }\end{array}$ & $\begin{array}{l}\text { Controls } \\
5\end{array}$ & $\begin{array}{l}\text { Asymptomatic } \\
\mathbf{3}\end{array}$ & $\begin{array}{l}\text { Moderate } \\
\quad 6\end{array}$ & $\underset{5}{\text { Advanced }}$ \\
\hline \multicolumn{5}{|l|}{ Clearance rate of aldosterone from plasma } \\
\hline Total $(L / \min )$ & $\begin{array}{c}1.247 \\
(0.860-1.64)\end{array}$ & $\begin{array}{c}1.000 \\
(0.835-1.29)\end{array}$ & $\begin{array}{c}0.878 \\
(0.721-1.21)\end{array}$ & $\begin{array}{c}0.487 \\
(0.304-0.74)\end{array}$ \\
\hline Renal (fraction of total) & $\begin{array}{c}0.107 \dagger \\
(0.085-0.143)\end{array}$ & $\begin{array}{c}0.143 \\
(0.102-0.203)\end{array}$ & $\begin{array}{c}0.122 \\
(0.091-0.165)\end{array}$ & $\begin{array}{c}0.108 \\
(0.061-0.144)\end{array}$ \\
\hline \multicolumn{5}{|c|}{ Fraction of extracted aldosterone conjugated in acid-labile form } \\
\hline $\begin{array}{l}\text { In kidneys (fraction of renal aldosterone } \rightarrow \\
\text { ALC) } \\
\text { In liver (fraction of hepatic aldosterone } \rightarrow \\
\text { ALC) }\end{array}$ & $\begin{array}{c}0.52 \dagger \\
(0.40-0.70) \\
0.040 \dagger \\
(0.03-0.062)\end{array}$ & $\begin{array}{c}0.49 \\
(0.37-0.57) \\
0.028 \\
(0.018-0.04)\end{array}$ & $\begin{array}{l}0.48 \\
(0.30-0.70) \\
0.033 \\
(0.017-0.055)\end{array}$ & $\begin{array}{c}0.34 \\
(0.21-0.65) \\
0.045 \\
(0.015-0.08)\end{array}$ \\
\hline \multicolumn{5}{|l|}{ Source of urinary acid-labile conjugate } \\
\hline $\begin{array}{l}\text { Renal (fraction of total urinary ALC pro- } \\
\text { duced in kidneys) }\end{array}$ & $\begin{array}{c}0.61 \dagger \\
(0.53-0.69)\end{array}$ & $\begin{array}{c}0.68 \\
(0.66-0.70)\end{array}$ & $\begin{array}{c}0.66 \\
(0.61-0.74)\end{array}$ & $\begin{array}{c}0.45 \\
(0.33-0.79)\end{array}$ \\
\hline \multicolumn{5}{|c|}{ Fraction of injected aldosterone- ${ }^{-3} \mathrm{H}$ excreted as acid-labile conjugate } \\
\hline Total (fraction of dose) & $\begin{array}{c}0.088 \\
(0.07-0.115)\end{array}$ & $\begin{array}{c}0.090 \\
(0.073-0.114)\end{array}$ & $\begin{array}{c}0.084 \\
(0.063-0.123)\end{array}$ & $\begin{array}{c}0.084 \\
(0.06-0.12)\end{array}$ \\
\hline
\end{tabular}

* The mean for each group is given (followed by range of individual patients in parentheses). ALC = acid-labile conjugate.

$\dagger$ Values with wider confidence limits (see text). 


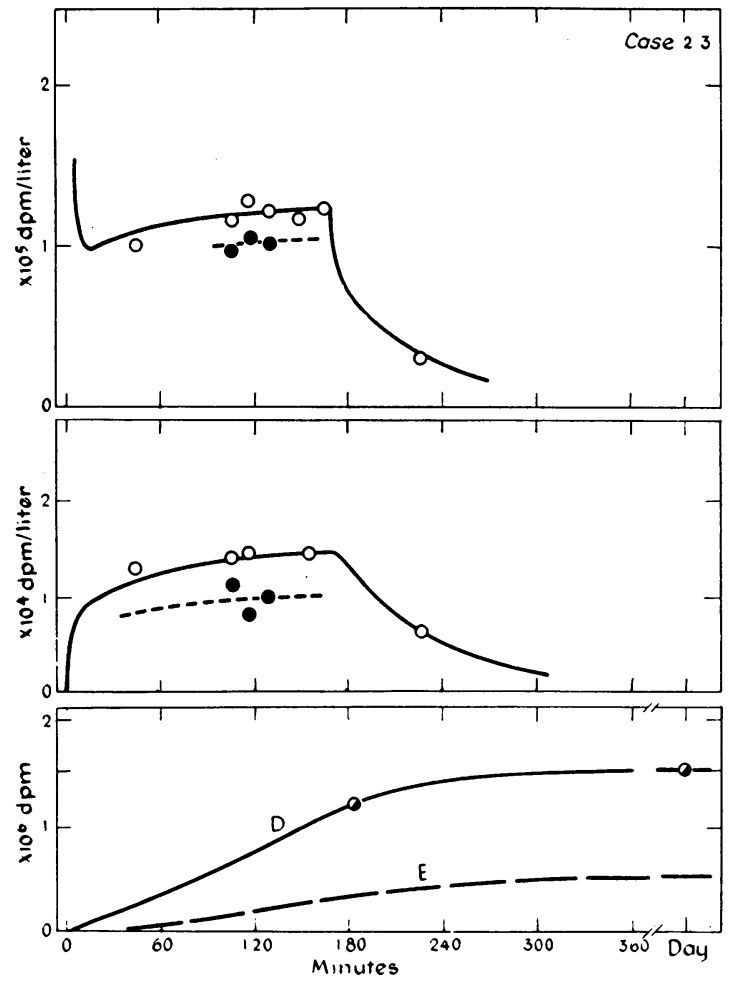

Fig. 7. Data from asymptomatic Patient 23. Top: Aldosterone- ${ }^{3} \mathrm{H}$ in arterial plasma (open circles, solid line) and in renal venous plasma (black circles, broken line). Middle: Acid-labile conjugate- ${ }^{3} \mathrm{H}$ in plasma from artery and renal vein. Bottom: Acid-labile conjugate- ${ }^{8} \mathrm{H}$ in urine (curve D) and fraction extracted from plasma (curve E). Initial dose, $1.8 \mu \mathrm{c}$ from 1 to 164 minutes.

jugate in renal venous plasma in a concentration higher than that in renal arterial plasma, within 3 minutes after intravenous injection of labeled aldosterone (Figures 4 and 5). In the five patients studied, the initial renal venous samples consistently contained more ${ }^{3} \mathrm{H}$-labeled acid-labile conjugate than was found in simultaneously drawn samples of arterial plasma. Approximately 10 minutes after the injection, the concentrations of conjugate in artery and renal vein were approximately equal. After 20 minutes of continuous infusion, the concentration of labeled conjugate in the renal vein was 35 to $57 \%$ below that in the artery, as the extraction ratio approached that observed in the steady state (compare Figures 8 and 9). In Patient 29, a prompt rise in labeled conjugate in the renal vein was also observed when a second load of aldosterone- ${ }^{3} \mathrm{H}$ was administered after 100 minutes of continuous infusion. These observations show that aldosterone is converted to acid-labile conjugate in the kidneys and that a reversible equilibrium permits conjugate to enter plasma from the kidneys.

Renal extraction of acid-labile conjugate during a continuous infusion of labeled aldosterone was observed in seven additional patients (Tables III and IV). The fraction of conjugate extracted from blood passing through the kidneys was 0.21 and 0.34 in two asymptomatic controls after 2 hours of infusion. The extraction ratio was higher in patients with congestive failure, averaging 0.35 in patients with minimal to moderate failure and 0.47 in patients with advanced failure. When the renal plasma flow is considered, it is evident that the quantity of conjugate extracted from plasma (curve $\mathrm{E}$ in Figures 7 and 8) can account for only a part of the conjugate excreted in the urine (data points and curve D).

Renal production of acid-labile conjugate must be assumed in order to account for $a$ ) the initial rise of concentration of conjugate in renal venous plasma above that in arterial plasma, $b$ ) the ap-
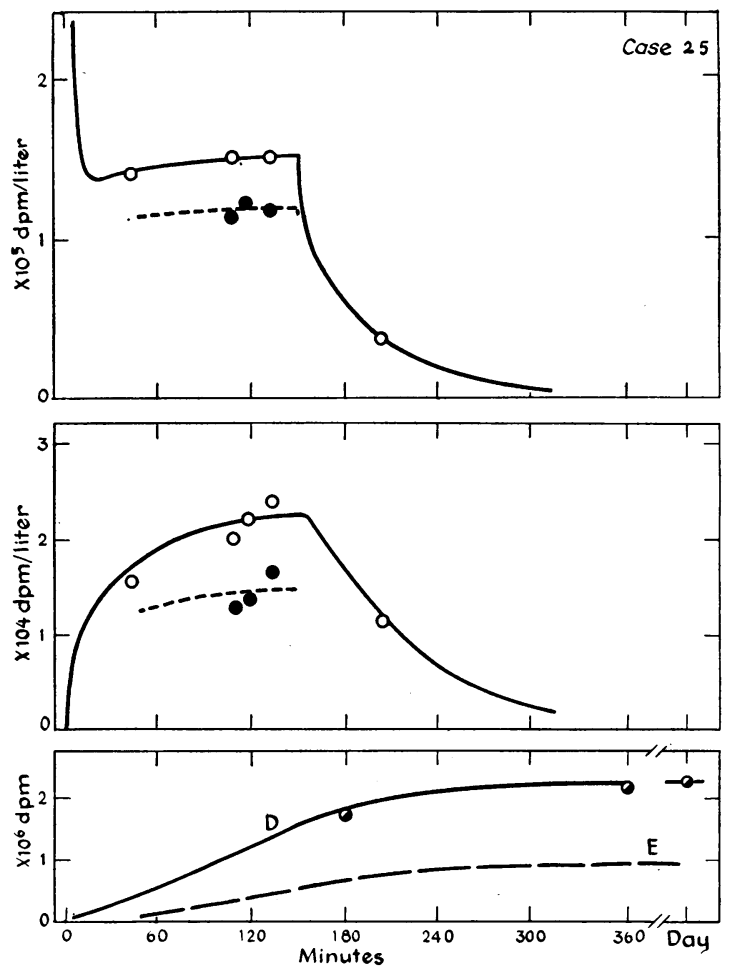

Fig. 8. Data from Patient 25 with moderate failURE. Displayed as in Figure 7. Initial dose, $1.9 \mu \mathrm{c}$. Infusion, $7.6 \mu \mathrm{c}$ from 1 to 146 minutes. 
pearance of more conjugate in urine than is extracted from plasma, and $c$ ) the rapid excretion of acid-labile conjugate in urine. The source of labeled conjugate formed in the kidneys is aldosterone $-{ }^{3} \mathrm{H}$, which is extracted from plasma but not excreted in urine. When the concentrations of aldosterone and conjugate in plasma from an artery and a renal vein are observed, together with the excretion of conjugate in urine, as shown in Figures 4 and 5 and 7 and 8 , the production of acid-labile conjugate by the kidneys can be estimated with a precision of $\pm 10 \%$. When the quantity of acid-labile conjugate produced in the kidneys is divided by the quantity of aldosterone extracted by the kidneys, the fraction is $0.45 \pm 0.08$ in two asymptomatic controls. Table $\mathrm{V}$ contains the fractions of conjugate formed from aldosterone extracted by the kidneys in 11 patients with congestive failure, from whom renal venous blood was analyzed.

The quantity of acid-labile conjugate formed in the kidneys can also be expressed as the fraction of total acid-labile conjugate excreted in urine. In two asymptomatic controls, this fraction is 0.68 \pm 0.02 . Similar results are obtained in early heart failure, but in most patients with advanced failure, the renal production of conjugate is lower, reflecting the fall in renal blood flow (Table V).

In the control group, the observed arterial and urinary conjugate levels are well matched by the model, with constants shown in Table III, but the fraction of conjugate formed in the kidneys can be estimated only within broad limits when renal venous samples are not ayailable. In Patient 20 , if renal production of conjugate is assumed to be negligible, the calculated rate of excretion of conjugate (curve F, Figure 9) is significantly slower than the rate observed, even if the renal extraction ratio of the conjugate is assumed to be higher than has ever been observed. To consider an opposite extreme, if $80 \%$ of the urinary conjugate is formed in the kidneys, the resulting curve $\mathrm{D}$ fits the observed rate of excretion of conjugate in urine, whereas the renal extraction ratio of 0.17 is somewhat below the least value, 0.21 , observed in a patient without significant impairment of circulatory function. In the absence of renal venous samples, we have required of estimates of renal metabolism and excretion by normal controls (Table V) not

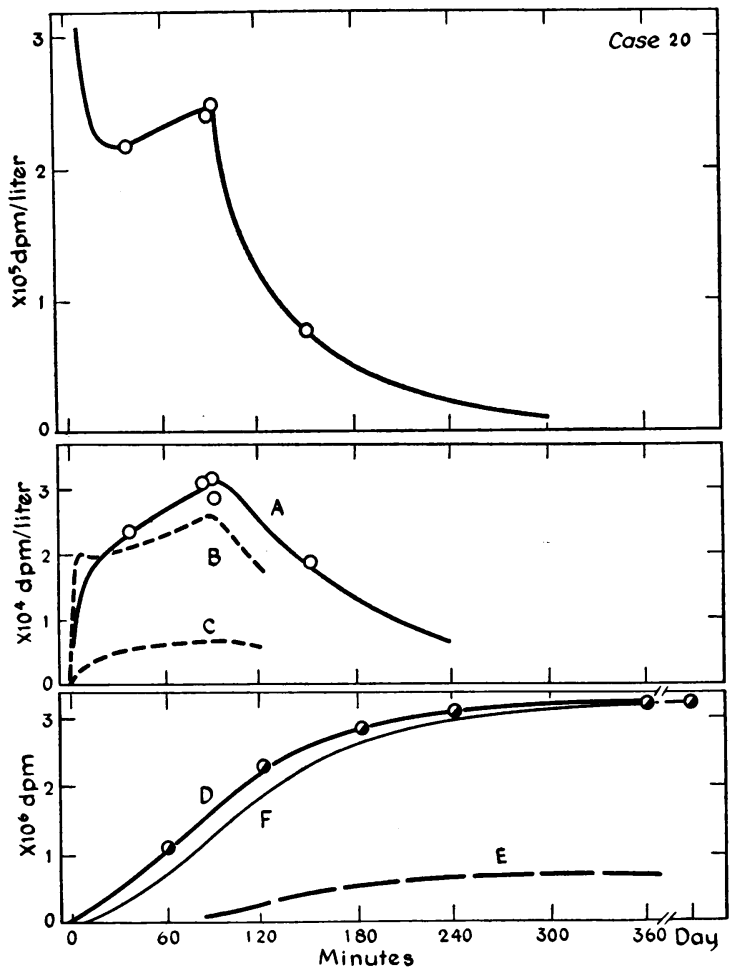

Fig. 9. Data from control, Subject 20. Top: Aldosterone $-{ }^{3} \mathrm{H}$ in arterial plasma. Middle: Acid-labile conjugate ${ }^{3} \mathrm{H}$ in plasma (curve $\mathrm{A}=$ arterial; curves $\mathrm{B}$ and $\mathrm{C}=$ renal vein). Bottom: Appearance of acid-labile conjugate ${ }^{3} \mathrm{H}$ in urine (curve $\mathrm{D}=$ best fit; curve $\mathrm{E}=$ extracted from plasma ; curve $\mathrm{F}=$ assuming all conjugate formed in liver). Initial dose, $5.3 \mu \mathrm{c}$. Infusion, $13.2 \mu \mathrm{c}$ from 1 to 89 minutes.

only that they fit the observed data, but also that the calculated extraction ratios of aldosterone and conjugate (shown in Table III) must fall within the wide limits of renal extraction observed in patients without circulatory disability.

Distribution of acid-labile conjugate affects the concentration of conjugate in plasma and its rate of excretion in the urine. The present formulation suggests an inner volume of distribution equal to plasma volume. The addition of an outer compartment (with a volume of 16 to $20 \mathrm{~L}$, equilibrating slowly with plasma) results in a more exact simulation of arterial concentration and urinary excretion of conjugate. The indicated volumes of distribution of the conjugate, which are smaller than those for free aldosterone, may reflect the exclusion of conjugate from cells, including red blood cells. 


\section{Discussion}

Distribution and clearance of aldosterone; comparison and interpretation of two models: Aldosterone- ${ }^{3} \mathrm{H}$ in plasma drawn from an artery or peripheral vein can be simulated by several mathematical models. The simplest effective model contains two pools, as shown by Tait and his colleagues (1). Since the initial volume of distribution is at least five times the volume of blood plasma, this model implies that labeled aldosterone in certain organs and tissues equilibrates very quickly with plasma after injection of a tracer dose. In Sulya, McCaa, Read, and Bomer's analyses (15) of organs of a rat after injection of aldosterone- ${ }^{3} \mathrm{H}$, the heart, kidneys, and spleen reached a maximal concentration of tritium within 5 minutes. Brain, liver, and fat reached a maximal concentration of tritium only after 15 to 30 minutes, a time period resembling that of the equilibration of Tait and colleagues' outer pool. Although the two pool model is the maximal acceptable simplification of a complex distribution system, its parameters can be accurately defined, and it is capable of reasonably good simulation of plasma aldosterone under various conditions.

The distribution of aldosterone in congestive failure differs from that in normal individuals. The changes in heart failure may be interpreted as a. smaller volume in rapid equilibrium with plasma in the two pool solution. The small inner volume, which approaches the plasma volume in heart failure, is considered to reflect a diminished rate of circulation, rather than a loss of tissue. In the three pool model, the inner volume is separated into intravascular and extravascular pools, which equilibrate rapidly in the normal control. This model describes the marked reduction in clearances in heart failure in more physiological terms, but it has only a limited advantage in its ability to simulate plasma aldosterone.

Congestive heart failure affects the regulation of plasma aldosterone in two different ways: a) Reduced hepatic extraction and clearance of aldosterone tend to increase the steady state concentration of aldosterone in plasma at any given rate of secretion $(5,6)$. This reduced rate of clearance would tend to prolong the half-time of aldosterone in plasma $(4,16)$. The half-time in plasma is also affected by distribution, however. b) The dynamic properties of the distribution and clearance of aldosterone are affected by heart failure in such a way that changes in aldosterone secretion can be followed by larger and more abrupt changes in plasma aldosterone than would be expected in normal controls. Not only does the volume of the inner pool fall, but the fraction of plasma aldosterone irreversibly cleared each minute from plasma may increase with the onset of heart failure. The reversible loss of aldosterone from plasma increases to a limited extent. There is a marked reduction in the fraction of aldosterone in the "outer pool" that returns each minute to the inner pool. This combination results in a lessened stability or "buffering" of plasma aldosterone, which shows more rapid and larger responses to changing rates of input than are seen in normal controls.

The uptake of aldosterone by the kidneys is rapid and reversible. The kidneys behave as a small volume, with a clearance near the renal plasma flow. There may be concentration of aldosterone above the plasma level (see Appendix). The ability of the kidney to conjugate aldosterone contributes to the quick responsiveness of the pool to rapidly falling aldosterone levels. The behavior of the renal compartment, predicted by the model, is in accord with the observations of Sulya and associates (15) in the kidneys of the rat. The fraction of arterial aldosterone extracted by the kidneys is remarkably stable despite wide variations in renal plasma flow.

Hepatic clearance of aldosterone falls progressively with advancing heart failure, as previously reported (5-7).

The alterations in aldosterone distribution and clearance in congestive failure reflect the reduced cardiac output and regional circulation. The early reduction in hepatic blood flow, and the marked fall in renal circulation in advanced failure, have been described; but the striking reduction in the rate of reversible distribution of aldosterone, beginning in early heart failure, suggests reduced circulation and exchange in the tissues, which make up the large "outer volume," and which may include fat, skin, and muscle, by inference from other studies $(15,17)$.

The acid-labile conjugate of aldosterone, thought to be aldosterone-18-glucuronide (18), has also been called the 3-oxoconjugate to distinguish it 
from other conjugates formed in the liver after reduction of the $\Delta^{4}$-3-ketone function. Evidence has been accumulating that this conjugate is formed not only in the liver, but also in the kidneys. Sandor and Lanthier (19) showed that renal tissue is capable of producing acid-hydrolyzable conjugates of aldosterone. The rapid excretion of conjugate, which was attributed to active renal secretion (12), resulted in apparent renal clearance approaching renal plasma flow (7). The kidneys take up more aldosterone- ${ }^{3} \mathrm{H}$ than they excrete, whereas conjugate- ${ }^{8} \mathrm{H}$ appears in urine at a rate greater than the rate of extraction of conjugate from plasma $(8,10)$.

Further evidence for the renal production of acid-labile conjugate has been added in this report. The appearance of labeled conjugate in the renal vein in greater concentration than that in the arterial plasma, suggested by the study of Bledsoe and co-workers (10), has been consistently demonstrated to occur immediately after the initial dose of labeled aldosterone in five patients. The excess concentration in the renal vein shows that acid-labile conjugate is produced in the kidneys and released into plasma. The concentration of labeled conjugate in renal vein later falls below that in the artery as the concentration of aldosterone- ${ }^{3} \mathrm{H}$ in plasma falls while the concentration of acid-labile conjugate rises. In the steady state, the kidney is acting both to form new conjugate and to extract preformed conjugate from the plasma.

These functions are defined by the model shown in Figure 1. When appropriate parameters are introduced into the equations, this model is capable of simulating the observed concentrations of conjugate in arterial and renal venous plasma and the rate of excretion in the urine. Simpler models do not predict the data accurately. The estimates of volumes and clearances of conjugate given in Tables III and IV are reasonable in physiologic terms.

The fractions of urinary acid-labile conjugate arising in the kidneys and in the liver have been difficult to estimate quantitatively. The calculation requires measurements of renal plasma flow, renal extraction ratio, and urinary excretion rate of conjugate after a steady state has been reached. The long equilibration times make these conditions difficult to accomplish with certainty. The analog computer has been useful in those cases in which equilibrium was not reached, and in relating the effects observed after loading doses to those occurring during continuous infusion.

Precise estimates of the renal contribution to the urinary acid-labile conjugate require the analysis of renal venous blood (see Results and Figure 9). The average renal production is $58 \%$ for the 13 patients from whom renal venous blood was drawn. Calculations indicate that two-thirds of the urinary acid-labile conjugate is formed in the kidneys in two asymptomatic patients and in six patients with moderate congestive failure. In five patients with advanced heart failure, the renal production of acid-labile conjugate is $45 \%$ of the total production.

Bledsoe and associates (10) have used an independent approach to compare the hepatic formation of acid-labile conjugate with that formed elsewhere in the body. The specific activity of urinary acid-labile conjugate was 47 to $101 \%$ higher when labeled aldosterone was given intravenously than when it was given by mouth (and presumably metabolized entirely by the liver). The simplest interpretation of their data would be that 33 to $50 \%$ of the conjugate is made in sites outside the liver, probably in the kidneys. In seven tests of four adrenalectomized patients, the average extrahepatic production was $40 \%$ of the urinary acid-hydrolyzable conjugate. The renal production of conjugate in our normal controls is estimated to be $61 \%$, but this estimate has wide confidence limits (approximately $\pm 20 \%$ ) because renal venous blood was not drawn from the controls. In the patients with advanced failure, the estimated renal production of $45 \%$ of the conjugate agrees well with Bledsoe and associates' estimates. The only significant differences between the estimates from the two laboratories appear in the higher values obtained from two asymptomatic subjects and the six patients with moderate congestive failure.

Taking into account all of these results, it would seem that between one-third and two-thirds of the acid-labile conjugate is formed in the kidneys. Some variation in the estimates in different groups of patients may be explained by differences in the proportions of aldosterone cleared from plasma by the kidneys and liver as a result of 
changing blood flow or enzymatic activity (Table V).

The distribution of acid-labile conjugate differs from that of aldosterone in that the clearances into the outer compartment are small. This difference cannot be explained by binding to plasma proteins, which appears to be less in the case of acid-labile conjugate than that observed for aldosterone. The estimated sizes of the inner and outer volumes of distribution are compatible with the plasma and interstitial fluid volumes.

Attention has been focused in this report on the acid-labile conjugate, but other metabolites, such as tetrahydroaldosterone can also be studied by similar techniques. Tetrahydroaldosterone glucuronide is the principal metabolite appearing in hepatic venous blood (8). Bledsoe and co-workers (10) found no appreciable extrahepatic production, and our observations on renal venous blood (20) offer no evidence of significant renal production of tetrahydroaldosterone glucuronide.

The metabolism of aldosterone in the liver is predominantly by reduction and conjugation (21, $22)$. On the average only $3.6 \%$ of aldosterone that enters the liver emerges undegraded as acidlabile conjugate (Table V). Renal conjugation in the acid-labile form accounts for at least onethird to two-thirds of the aldosterone extracted by the kidneys. This estimate may prove to be lower than the true value if unaccounted losses occur during acid hydrolysis (18).

\section{Summary}

The disappearance of aldosterone ${ }^{3} \mathrm{H}$ from plasma has been measured in a series of $21 \mathrm{pa}$ tients with circulatory status varying from normal to advanced congestive heart failure. The results confirm earlier reports of reduced hepatic clearance of aldosterone in heart failure, which tends to increase the concentration of aldosterone in plasma for any constant rate of secretion. Current findings also show that reduced exchange of aldosterone between plasma and other compartments in congestive failure can give rise to unusually large and rapid changes in plasma aldosterone in response to changing rate of administration or secretion.

Aldosterone uptake by the kidneys has been studied by analysis of arterial and renal venous blood and by measurement of renal plasma flow. The kidneys behave as a small compartment in which aldosterone is in rapid equilibrium with plasma. About $20 \%$ of aldosterone is extracted from plasma passing through the kidneys over a wide range of renal blood flow. Most of the extracted aldosterone is conjugated or degraded; only a small fraction is excreted unchanged in the urine.

The formation, distribution, and excretion of acid-labile conjugate (aldosterone-18-glucuronide) have been represented by a model, which simulates the flow of tracer from injection of labeled aldosterone through excretion of conjugate in urine. The model has been tested in various experimental conditions, in which the concentrations of labeled aldosterone and conjugate in arterial and renal venous plasma, as well as the appearance of conjugate in urine, can be reproduced.

Acid-labile conjugate is formed both in the kidneys and in the liver. Most of the conjugate formed in the kidneys is rapidly excreted into urine, but an appreciable flow of labeled conjugate from kidneys to plasma can be demonstrated immediately after a loading dose of aldosterone $-{ }^{3} \mathrm{H}$.

The average renal production is estimated to be $58 \%$ of the total acid-labile conjugate in urine. The clearances of aldosterone from plasma fall with advancing heart failure, but the reductions in hepatic and renal clearance are not in a fixed proportion. The contributions of acid-labile conjugate by the liver and kidneys appear to vary with their uptake of aldosterone and with enzymatic activity. Between one-third and two-thirds of the aldosterone that enters the kidneys is converted to acid-labile conjugate. Tetrahydroaldosterone glucuronide is the principal metabolite released by the liver, in which an average of $3.6 \%$ of aldosterone is conjugated in the acid-labile form.

\section{Appendix}

The equations for each compartment take the same form as the one given in the Methods section. The terms in each equation are indicated by the arrows that enter or leave the compartment in Figure 1.

The outer space of aldosterone distribution $\left(\mathrm{V}_{2}\right)$ is not anatomically defined. It may comprise a number of heterogeneous tissues and organs. It cannot be sampled, and its volume is a convenient abstraction. The values given in Table III assume that the clearances between compartments 1 and 2 are equal. If the binding of al- 
dosterone by plasma proteins (23) is taken into account, $\mathrm{V}_{2}$ exceeds body water or even body weight, indicating that sites of concentration or binding probably exist in the outer space.

The technique of reading out concentration in the renal vein is as follows. The net flow of labeled aldosterone from plasma to the kidneys, $d Q_{41} / d t=Q_{1} \lambda_{41}-Q_{4} \lambda_{14}=$ $\mathrm{C}_{1} \mathrm{CL}_{41}-\mathrm{C}_{4} \mathrm{CL}_{14}$. By definition, $\mathrm{C}_{1}=$ arterial aldosterone concentration (a), and $\mathrm{CL}_{41}$ has been set to equal renal plasma flow (RPF). If $\mathrm{k}=\mathrm{CL}_{14} / \mathrm{CL}_{41}$, then $\mathrm{dQ}_{41} /$ $\mathrm{dt}=\mathrm{RPF}\left(\mathrm{a}-\mathrm{kC}_{4}\right)$. If $\mathrm{v}$, the concentration of aldosterone in renal vein, is substituted for $\mathrm{kC}_{4}$, this equation expresses the Fick principle. The value of $\mathbf{v}$ can be conveniently read from either the analog or digital computer.

Although we have not attempted to define the volume of the renal compartment, it is a factor in $\lambda_{14} . \lambda_{14}=$ (RPF) $\left(k / V_{4}\right)$. We can compute $k / V_{4}$. At equilibrium, $\mathrm{k}$ is the ratio of the concentration of aldosterone in renal venous plasma to that in kidney. If we assume that the volume of the renal pool is $300 \mathrm{ml}$, a concentration of aldosterone in the kidneys between three and four times the concentration in plasma is indicated by the data. Since this relative concentration fits the published analyses of rat kidneys (15), the assumption is considered acceptable and has been used in the computations.

The turnover of aldosterone and conjugate in compartments 6 and $6^{\prime}$ is very rapid. The appearance of conjugate has been simulated by using a single compartment, with a volume of $4 \mathrm{~L}$ and a clearance of $2 \mathrm{~L}$ per minute. These values can be varied over a considerable range without much effect. The percentage of aldosterone emerging as acid-labile conjugate (Table V, data line 4), however, requires careful adjustment.

\section{Acknowledgments}

The authors are indebted to the Endocrinology Study Section, National Institutes of Health, for gifts of tritium- and ${ }^{14}$ carbon-labeled aldosterone; to Drs. Harold Hubis and Robert Kleiger for cardiac catheterizations; and to Mmes. B. Burckhardt, P. Hooz, and M. L. Rao for expert work in the laboratory. Drs. J. P. Bunker and J. W. Bellville generously made available time on the electrical analog computer (Beckman Ease). We wish to thank Dr. Mones Berman of the Office of Mathematical Research, National Institute of Arthritis and Metabolic Diseases, for providing tapes for the SAAM-22 program; and Dr. J. W. Farquhar and Mr. Edward Brown for their help in introducing this program at the Stanford Computation Center.

\section{References}

1. Tait, J. F., S. A. S. Tait, B. Little, and K. R. Laumas. The disappearance of $7-\mathrm{H}^{3}-d$-aldosterone in the plasma of normal subjects. $\mathrm{J}$. clin. Invest. 1961, 40, 72.

2. Davis, J. O., M. J. Olichney, T. C. Brown, and P. F. Binnion. Metabolism of aldosterone in sev- eral experimental situations with altered aldosterone secretion. J. clin. Invest. 1965, 44, 1433.

3. Tait, J. F., B. Little, S. A. S. Tait, and C. Flood. The metabolic clearance rate of aldosterone in pregnant and nonpregnant subjects estimated by both single-injection and constant-infusion methods. J. clin. Invest. 1962, 41, 2093.

4. Ayers, C. R., J. O. Davis, F. Lieberman, C. C. J. Carpenter, and M. Berman. The effects of chronic hepatic venous congestion on the metabolism of $d, l$-aldosterone and $d$-aldosterone. J. clin. Invest. 1962, 41, 884.

5. Tait, J. F., J. Bougas, B. Little, S. A. S. Tait, and C. Flood. Splanchnic extraction and clearance of aldosterone in subjects with minimal and marked cardiac dysfunction. J. clin. Endocr. 1965, 25, 219.

6. Camargo, C. A., A. J. Dowdy, E. W. Hancock, and J. A. Luetscher. Decreased plasma clearance and hepatic extraction of aldosterone in patients with heart failure. J. clin. Invest. 1965, 44, 356.

7. Luetscher, J. A., C. A. Camargo, E. W. Hancock, A. J. Dowdy, and G. W. Nokes. Observations of aldosterone metabolism in congestive heart failure Trans. Ass. Amer. Phycns 1964, 77, 224.

8. Luetscher, J. A., E. W. Hancock, C. A. Camargo, A. J. Dowdy, and G. W. Nokes. Conjugation of $1,2{ }^{3} \mathrm{H}$-aldosterone in human liver and kidneys, and renal extraction of aldosterone and labeled conjugates from blood plasma. J. clin. Endocr. 1965, 25, 628.

9. Luetscher, J. A., C. A. Camargo, R. A. Cheville, E. W. Hancock, A. J. Dowdy, and G. W. Nokes. Conjugation and excretion of aldosterone: testing of models with an analog computer. U.S.-Japan Conference on Steroid Dynamics, May 1965. New York, Academic Press, 1966.

10. Bledsoe, T., G. W. Liddle, A. Riondel, D. P. Island, D. Bloomfield, and B. Sinclair-Smith. Comparative fates of intravenously and orally administered aldosterone: evidence for extrahepatic formation of acid-hydrolyzable conjugate in man. J. clin. Invest. 1966, 45, 264.

11. Cheville, R. A., E. W. Hancock, J. A. Davis, A. J. Dowdy, and J. A. Luetscher. Renal extraction and clearance of $0-\mathrm{I}^{131}$-hippurate from plasma at low concentrations. Clin. Res. 1966, 14, 183.

12. Gfeller, J., and W. Siegenthaler. Die renale Clearance des Aldosterons und seiner Hauptmetabolite beim Menschen. Acta endocr. (Kbh.) 1965, 49, 510.

13. Berman, M. The formulation and testing of models. Ann. N. Y. Acad. Sci. 1963, 108, 182.

14. Coppage, W. S., Jr., D. P. Island, A. E. Cooner, and G. W. Liddle. The metabolism of aldosterone in normal subjects and in patients with hepatic cirrhosis. J. clin. Invest. 1962, 41, 1672.

15. Sulya, L. L., C. S. McCaa, V. H. Read, and D. Bomer. Uptake of tritiated aldosterone by rat tissues. Nature (Lond.) 1963, 200, 788. 
16. Wolff, H. P., D.' Lommer, J. Jahnecke, and $M$. Torbica. Hyperaldosteronism in oedema in Aldosterone, E. E. Baulieu and P. Robel, Eds. Philadelphia, F. A. Davis, 1964, pp. 471-86.

17. Wade, O. L., and J. M. Bishop. Cardiac Output and Regional Blood Flow. Oxford, Blackwell, 1962, pp. 134-48.

18. Underwood, R. H., and J. F. Tait. Purification, partial characterization and metabolism of an acid labile conjugate of aldosterone. J. clin. Endocr. 1964, 24, 1110.

19. Sandor, T., and A. Lanthier. The metabolism of aldosterone. II. Studies "in vitro" and "in vivo" in man. Acta endocr. (Kbh.) 1962, 39, 87.

20. Luetscher, J. A., R. A. Cheville, E. W. Hancock, A. J. Dowdy, and G. W. Nokes. Further stud- ies on distribution, conjugation, and excretion of aldosterone. Proceedings of the Second International Congress on Hormonal Steroids. Amsterdam, Excerpta Medica Foundation, 1966.

21. Ulick, S., K. Kusch, and J. T. August. Correction of the structure of a urinary metabolite of aldosterone. J. Amer. chem. Soc. 1961, 83, 4482.

22. Kelly, W. G., L. Bandi, and S. Lieberman. Isolation and characterization of human urinary metabolites of aldosterone. III. Three isomeric tetrahydro metabolites. Biochemistry 1962, 1, 792.

23. Meyer, C. J., D. S. Layne, J. F. Tait, and G. Pincus. The binding of aldosterone to plasma protein in normal, pregnant, and steroid-treated women. J. clin. Invest. 1961, 40, 1663. 